\title{
Costs of performance based maintenance for local roads: Case study Albania
}

\author{
Igor Jokanović ${ }^{1}$, Bojana Grujić ${ }^{2}$, Dragana Zeljić ${ }^{2}$ Žarko Grujić $^{2}$, Mila Svilar ${ }^{1}$ \\ ${ }^{1}$ University of Novi Sad, Faculty of Civil Engineering, Subotica \\ e-mail: jokanovici@gf.uns.ac.rs, mila.svilar@gmail.com \\ ${ }^{2}$ University of Banja Luka, Faculty of Architecture, Civil Engineering and Geodesy, Banja Luka \\ e-mail: bojana.grujic@aggf.unibl.org, dragana.zeljic@aggf.unibl.org, zarko.grujic@aggf.unibl.org
}

\begin{abstract}
The provision and maintenance of road infrastructure is a major global business, consequently it is essential that road maintenance services are provided in the most cost effective manner. Without regular maintenance, roads can rapidly fall into disrepair, preventing realization of the longer term impacts of road improvements on development, such as increased agricultural production and growth in school enrollment, which is of particular importance for a network of local (access) roads. Inadequate local roads maintenance in Albania is proposed to be solved by implementing performance based maintenance approach for which the costing exercise is presented within the paper.
\end{abstract}

Key words: local roads, performance based maintenance, maintenance costs, road user costs

\section{Introduction}

Road authorities worldwide face mounting problems with maintaining the serviceability of their road networks [1]. Over the years, there has been a gradual progression in road maintenance philosophy. In general terms, it was traditionally carried out directly by the road authority with its own maintenance organization supplementing its own capacity, to a greater or lesser degree, by contracting some works to contracting companies. This period has been followed by steady rise in the contracted element of the works with many authorities reaching the point where all maintenance activity is carried out by contractors applying traditional methods of contracting and measurement of works under the authority's supervision. Over the last 20 years, however, there has been a steady rise in implementing contracted maintenance through the use of performance based methods. Under this methodology, the contract is based on the concept of payment for specified results (resulting in a well maintained road) based on the contractor meeting specified standards of performance rather than measuring and paying for the quantities of work which he actually does, i.e. based on outputs. This contracting method is generally considered to be more cost effective than the traditional, input based methods using measurement of units of work undertaken with payment at unit rates. 
The essence of the Performance Based Maintenance (PBM) concept is that the contractor undertakes to carry out all necessary maintenance to a road or roads to keep them at a predetermined required standard. There is no measurement of the volume of works carried out and the agency does not dictate to the contractor what should be done or when it should be done. The contractor is free to organise the work required as and when it suits him subject only to maintaining the road at the specified standard. The contractor is responsible for quality control, both of the overall standard of maintenance and of the details of materials used and work performed. His performance is measured by monitoring a specific set of measurable values related to road condition.

The local roads system in Albania is expected to have a total length in excess of $20,000 \mathrm{~km}$. Average expenditure on local roads maintenance in Albania is in the range of EUR 235-290 (ALL-Albanian Lek 32,000-40,000) per $\mathrm{km}$ per year [2]. This is extremely low. They effectively cover the costs of routine maintenance only, with no allowance for periodic maintenance or for improvements incurred as a result of inadequate maintenance. Local authorities generally seemed to regard bituminous surfaces as "maintenance free" allowing them to deteriorate until a contract had to be let for an improvement to make good the damage. Where structural failure of paved roads occurred the affected sections were included in future rehabilitation/reconstruction contracts. No effort seems to have been made to consider or fund this work as maintenance. A substantial element of maintenance works was, effectively, offloaded onto the capital improvements budget, thereby saving immediate maintenance expenditure at the expense of greatly increased future costs.

The central issue to be addressed is the inadequate maintenance of Albania's local road network, and the need to change the maintenance philosophy from a reactive approach to a preventive approach. Analysis showed that this should be achieved by introducing a performance based approach [2]. Following the proposal of Level of Service (LoS) concept and relevant Maintenance Standards (MSs) for the Albanian local roads system, costing element of the system had to be prepared, and it is detailed further down below.

\section{Performance based maintenance of local roads in Albania}

The proposed system defines the appropriate MS to preserve a set LoS for each functional road class and traffic level, and specifies the tasks and their frequency of execution for each MS. In general, the difference between MS lies in the frequency of execution or the permitted delay before execution of the required tasks rather than in the actual tasks themselves; in some cases, the MS also considers an acceptable level of deficiency in some road quality. The differences between the MSs result from the need to provide numerical definitions for the different intensity of maintenance operations necessary to provide the required LoS having regard to differing road classes and traffic levels. Through the use of a wide range of performance indicators they define the allowable deviations from the perfect condition and the length of time which is permitted for the rectification of identified failings or defects.

The proposal is to establish five different LoS [2]: excellent, good, satisfactory, poor and bad. LoS relate to road user expectations and the definition of each level varies with road class and traffic level. At the same time a system of maintenance classification using five different levels of maintenance is proposed [2]. These are referred to as MS1, the highest standard of maintenance, running down to MS5, forming the lowest fixed standard. In addition to the five 
fixed standards, further - basic access standard is also proposed. This would require simply that access should be preserved with no measured maintenance parameters other than some measure of the practicable speed at which the road could be driven over. The following tables (Table 1 and 2) illustrate the relationship between LoS and MSs for elements of the local roads system (urban roads/streets and rural roads) at different traffic levels.

Table 1: Levels of service for urban roads/streets [2]

\begin{tabular}{|c|c|c|c|c|c|}
\hline traffic levels & \multicolumn{5}{|c|}{ maintenance standard } \\
\cline { 2 - 6 } AADT [veh/day] & MS1 & MS2 & MS3 & MS4 & MS5 \\
\hline$>1,000$ & satisfactory & satisfactory & poor & bad & bad \\
$500-1,000$ & good & satisfactory & satisfactory & poor & bad \\
$250-500$ & excellent & good & satisfactory & satisfactory & poor \\
$100-250$ & excellent & excellent & good & satisfactory & satisfactory \\
$<100$ & excellent & excellent & excellent & good & satisfactory \\
\hline
\end{tabular}

Table 2: Levels of service for rural roads [2]

\begin{tabular}{|c|c|c|c|c|c|}
\hline traffic levels & \multicolumn{5}{|c|}{ maintenance standard } \\
\cline { 2 - 6 } AADT [veh/day] & MS1 & MS2 & MS3 & MS4 & MS5 \\
\hline$>1,000$ & good & good & satisfactory & poor & bad \\
$500-1,000$ & excellent & good & good & satisfactory & poor \\
$250-500$ & excellent & excellent & good & satisfactory & poor \\
$100-250$ & excellent & excellent & excellent & good & satisfactory \\
$<100$ & excellent & excellent & excellent & excellent & good \\
\hline
\end{tabular}

Performance indicators are provided for all key aspects or tasks of road maintenance. The frequency and effectiveness of the actions which are given in the standards define the routine requirements to meet the specified service quality levels.

\section{Costs analysis}

Cost estimates for routine maintenance of local roads in accordance with the proposed LoS concept were established on the basis of official rates for materials, equipment and staff at the municipality level. However, in the absence of actual data on local roads inventory and condition, it was only possible to establish a kind of hypothetical case over a period of time with assumed parameters (particularly regarding condition of pavement). Where no maintenance program is in place, cost calculations do not have to be $100 \%$ precise at the beginning. The main point is to get started.

Routine maintenance of paved roads predominantly depends on the level of carriageway damage and relevant pavement repair activities (for instance patching, rutting repair, crack sealing, etc.), and the level of damage is normally in direct relation to traffic level that particular road carries. Maintenance of the remaining elements within the road's right-of-way is mainly related to cyclic activities and can be calculated with a relatively high level of accuracy.

The following assumptions have been made for calculation of routine maintenance costs [3]: 
- 10 years planning period;

- unit section length of $1 \mathrm{~km}$;

- single two-lane carriageway with platform width of $6 \mathrm{~m}$ (which can be assumed as average platform width of Albanian paved local roads);

- 0.5 m gravel shoulders;

- traffic flow in two directions;

- representative values of traffic volume: 250 - 500 - 1,000 - 2,500 veh/day;

- traffic flow composition as defined in Table 3 resulting from statistical analysis of available traffic survey data;

$-2.0 \%$ traffic growth rate;

- pavement condition characterized by two IRI (International Roughness Index) values, i.e. $\mathrm{IRI}=2 \mathrm{~m} / \mathrm{km}$ (new road) and IRI=5 m/km (older road).

Table 3: Traffic flow composition [\%] [3]

\begin{tabular}{|c|c|c|c|c|}
\hline traffic band [veh/day] & passenger cars & minibuses & buses & trucks \\
\hline$\leq 1,000$ & 61 & 28 & 1 & 10 \\
$>1,000$ & 68 & 18 & 4 & 10 \\
\hline
\end{tabular}

\subsection{Calculation of works unit rates}

Tables below (Table 4 and Table 5) show summary of basic unit rates for fundamental maintenance requirements in line with the proposed LoS approach. Because Albania consists of certain portion of the country that is not normally being exposed to severe winter weather and snowfalls, the rates were calculated for two cases. The first case is for use in those areas where winter maintenance service is not applicable, or at least, not normally applicable. Where winter maintenance is required the calculation must change to include this.

Table 4: Unit rates for routine maintenance of paved roads (no winter service) [ALL] [3]

\begin{tabular}{|l|c|c|c|c|c|c|}
\hline \multicolumn{1}{|c|}{ maintenance standard } & BM & MS5 & MS4 & MS3 & MS2 & MS1 \\
\hline $\begin{array}{l}\text { routine maintenance per } \\
\text { kilometer }\end{array}$ & 141,240 & 159,860 & 277,340 & 343,700 & 573,260 & 602,020 \\
$\begin{array}{l}\text { routine maintenance per } \\
\text { kilometer (without marking) }\end{array}$ & 41,240 & 59,860 & 77,340 & 143,700 & 173,260 & 202,020 \\
\hline
\end{tabular}

Table 5: Unit rates for routine maintenance of paved roads (with winter service) [ALL] [3]

\begin{tabular}{|l|c|c|c|c|c|c|}
\hline \multicolumn{1}{|c|}{ maintenance standard } & BM & MS5 & MS4 & MS3 & MS2 & MS1 \\
\hline $\begin{array}{l}\text { routine maintenance per } \\
\text { kilometer }\end{array}$ & 136,080 & 150,920 & 264,230 & 318,950 & 541,220 & 562,990 \\
$\begin{array}{l}\text { winter maintenance per } \\
\text { kilometer } \\
\text { routine and winter maintenance } \\
\text { per kilometer }\end{array}$ & 36,600 & 36,600 & 36,600 & 45,300 & 56,175 & 62,700 \\
\hline
\end{tabular}


The basic access maintenance (BM), as well as MS5 assume a lengthman system operated under direct labor. It assumes that some accident damage will require repair each year and that gravel shoulders will need limited reshaping once per year. This estimate assumes one lengthman per $10 \mathrm{~km}$ of road, but expected to be living on the road length for which he is responsible and to require no transport. Furthermore, basic access LoS also assumes that pothole patching shall be performed once a year for the most severe locations (approximately $50 \%$ of damaged area). On the other side, MS4 to MS1 assume team(s) of specialized road workers performing multiple tasks during their duty service, and supported by heavy equipment and plant when required during specialized and extensive operations.

As the pavement ages there will be a steadily increasing workload of pavement maintenance. This is valued through number of pavement repair activities (patching, crack sealing, etc.).

\subsection{Condition of roads}

In order to estimate condition of roads, as well as 10-year routine maintenance costs, Highway Development and Management Model 4 (HDM 4) was utilized. Results presented in the following figures (Figures 1 to 4 ) show how condition of pavement (IRI) develops through the analyzed period, depending on the MS for various levels of traffic. Roughness, presented through IRI value, is key indicator of LoS providing good measure of road user experience and extend of physical road deterioration.
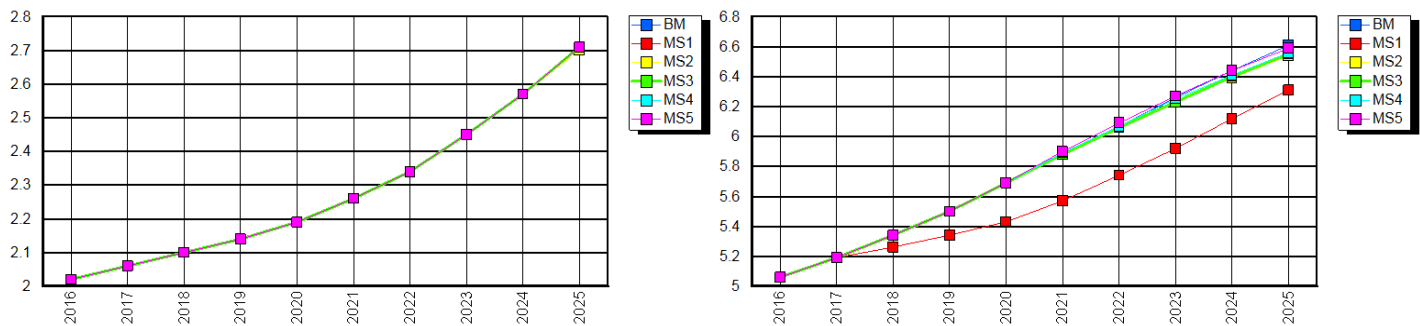

Figure 1: Average roughness (IRI [m/km]) for new and older road, traffic $250 \mathrm{veh} /$ day [3]
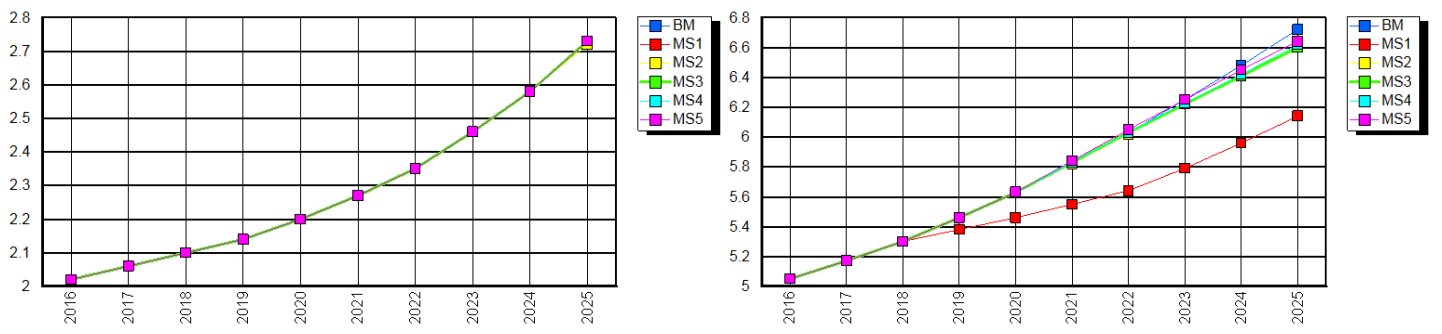

Figure 2: Average roughness (IRI [m/km]) for new and older road, traffic $500 \mathrm{veh} /$ day [3]
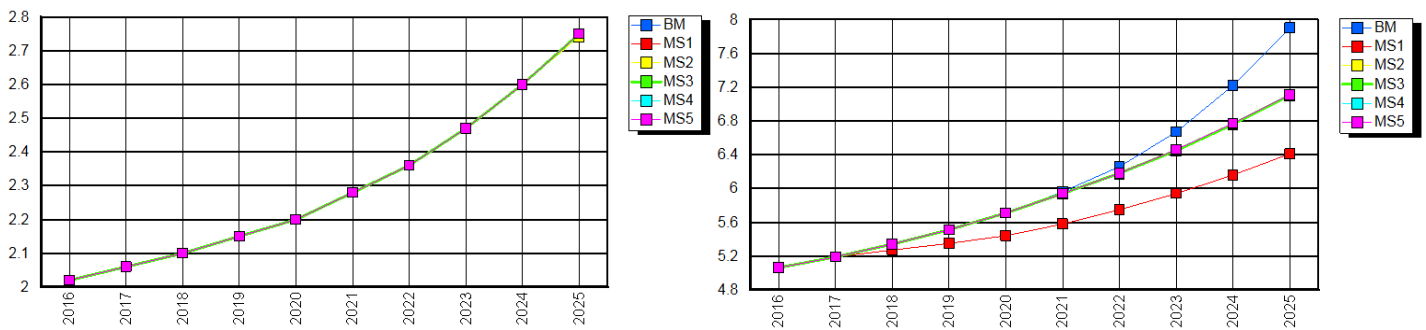

Figure 3: Average roughness (IRI [m/km]) for new and older road, traffic 1,000 veh/day [3] 

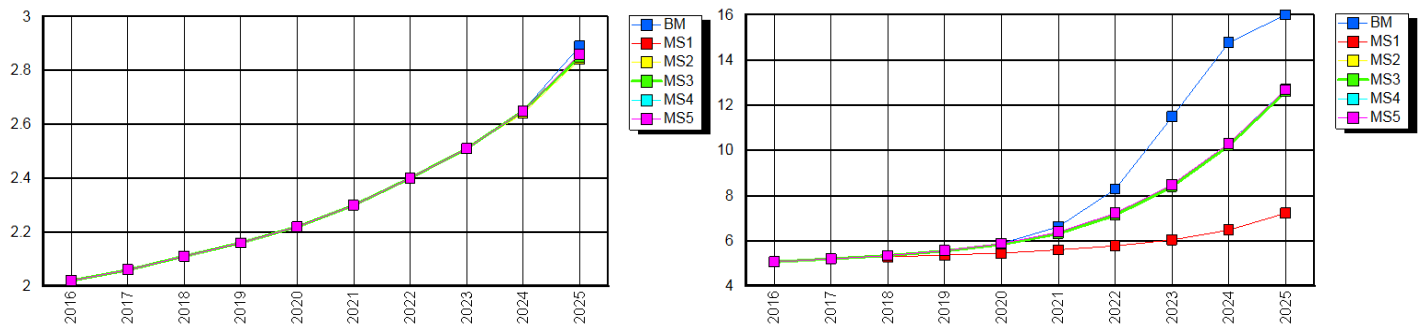

Figure 4: Average roughness (IRI [m/km]) for new and older road, traffic 2,500 veh/day [3]

As expected and due to normally rather low traffic volumes on local roads, in case of new road with initial roughness of IRI $=2 \mathrm{~m} / \mathrm{km}$ (Figures 1 to 4 , left side), progress of deterioration or increase of IRI values is relatively slow and reaches value of about 2.75 (still very good or almost excellent condition after 10 years). Only with 2,500 veh/day, deterioration will reach a higher values, however still significantly low so that some "heavier" form of maintenance will not be triggered. Another important conclusion is that road condition, benefiting from low traffic volumes, is mostly inert to different MSs applied. In the case of higher traffic volumes that may be occurring at the urban or sub-urban local roads (having several thousands of vehicles per day), the speed of deterioration would probably be higher and IRI would increase more rapidly, while the difference between MSs would be notable. This may be visible on Figure 4 (left side) by the end of the analysis period (year 2025) where some significant damage is appearing on the road that cannot be properly repaired by lower LoS.

To the contrary, for the older road (Figures 1 to 4, right side) difference in condition as a consequence of applied MS is clearly visible showing that MS1 would provide remarkably better condition than other MSs. This goes to the level that the older road subject to initial 2,500 veh/day (Figure 4, right side) would still be in relatively good condition for driving, providing not so bad level of comfort to users, if maintained under regime MS1 comparing to condition provided by MS2 to MS4 and BM. These lower LoS would practically lead the road to very bad condition, with low vehicle speeds and high user costs.

Apart from indicating the LoS, roughness is a key indicator for periodic maintenance interventions. Through roughness road authority can establish key IRI levels for each class of road for a variety of traffic levels at which periodic maintenance interventions are economically optimal.

\subsection{Routine maintenance costs}

The same analysis was used to establish routine maintenance costs. Costs for routine maintenance over a 10-year period have been built up while annualized costs per $\mathrm{km}$ of road under routine maintenance are presented in Table 6.

Normally, maintenance costs increase significantly with the maintenance standard applied (ratio between MS1 and BM ranges from 3.5 to 4.3). Again, traffic volume is not so important factor due to its low value (up to 5\% increase in cost due to increase of traffic load).

A winter maintenance requirement increases the general maintenance cost appreciably, but is not a great contributor for higher MS. This is because the overall maintenance costs are driven more by routine maintenance. However, increase is higher for lower MS, and can be in the range of $20 \%$ for lower $\operatorname{LoS}$ where routine maintenance activities are literary performed to provide access all year round. 
Table 6: Annualized routine maintenance costs per km for analyzed paved roads and various traffic volumes, depending on applied MS [ALL] [3]

\begin{tabular}{|c|c|c|c|c|c|c|c|c|}
\hline $\begin{array}{l}\text { traffic volume } \\
\text { [veh/day] }\end{array}$ & road & winter & $\mathrm{BM}$ & MS5 & MS4 & MS3 & MS2 & MS1 \\
\hline \multirow{4}{*}{$\begin{array}{l}250 \\
\text { (low) }\end{array}$} & \multirow{2}{*}{ new } & no & 141,256 & 159,860 & 346,865 & 346,865 & 577,611 & 606,371 \\
\hline & & yes & 172,696 & 187,520 & 300,830 & 367,415 & 601,746 & 630,041 \\
\hline & \multirow{2}{*}{ older } & no & 141,851 & 160,562 & 278,032 & 349,175 & 578,731 & 639,256 \\
\hline & & yes & 173,291 & 188,222 & 301,522 & 369,725 & 602,866 & 662,926 \\
\hline \multirow{4}{*}{$\begin{array}{c}500 \\
\text { (medium) }\end{array}$} & \multirow{2}{*}{ new } & no & 141,264 & 159,860 & 277,340 & 346,901 & 577,623 &, 383 \\
\hline & & yes & 172,704 & 187,520 & 300,830 & 367,451 & 601,758 & 630,053 \\
\hline & \multirow{2}{*}{ older } & & 141,994 & 160,733 & 278,201 & 349,467 & 579,016 & 652,377 \\
\hline & & yes & 173,434 & 188,393 & 301,691 & 370,017 & 603,151 & 676,047 \\
\hline \multirow{4}{*}{$\begin{array}{l}1,000 \\
\text { (high) }\end{array}$} & \multirow{2}{*}{ new } & no & 141,282 & 159,860 & 277,340 & 346,924 & 580,293 & 608,417 \\
\hline & & yes & 172,722 & 187,520 & 300,830 & 367,474 & 604,428 & 632,087 \\
\hline & \multirow{2}{*}{ older } & no & 142,890 & 161,647 & 282,686 & 353,490 & 585,012 & 645,417 \\
\hline & & yes & 174,330 & 189,307 & 306,176 & 374,040 & 609,147 & 669,087 \\
\hline \multirow{4}{*}{$\begin{array}{c}2,500 \\
\text { (very high) }\end{array}$} & \multirow{2}{*}{ new } & no & 141,543 & 160,265 & 306,814 & 377,590 & 607,564 & 636,324 \\
\hline & & yes & 172,983 & 187,925 & 330,304 & 398,140 & 631,699 & 659,994 \\
\hline & \multirow{2}{*}{ older } & no & 145,470 & 164,049 & 315,275 & 386,287 & 615,823 & 672,483 \\
\hline & & yes & 176,910 & 191,709 & 338,765 & 406,837 & 639,958 & 696,153 \\
\hline
\end{tabular}

The rate for old roads can be much higher than for new roads, in particular for higher MS, because the estimate practically foresees some effort to bring these roads up to a reasonable pavement standard. However, it must be noted that routine maintenance, without application of some periodic treatment or pavement rehabilitation, cannot significantly contribute to improvement of pavement condition as presented on Figures 1 to 4 (right side) where steady deterioration at rather high gradient is visible.

The new road cases practically assume that no (or very small volume) pavement maintenance will be required during the first several years and that real pavement maintenance commences only in year 7 or 8 , depending on traffic volume and MS. Deviation from this rule is shown in the case of very high traffic volume $(2,500 \mathrm{veh} /$ day and higher) where some pavement maintenance activities should start from year 2 or 3 depending on the MS.

The older road cases provide a higher level of expenditure on pavement maintenance from the very beginning of the analysis period. This is related to worse condition of pavement comparing to new road. Roads with high IRI values are more susceptible to slight increases in traffic volume or decreases in MS than those with lower IRI. Presented analysis clearly shows that paved roads should not be considered to be maintenance free, exactly opposite to general practice with local roads in Albania.

\subsection{Road user costs}

Table 7 shows summary of estimated Road User Costs (RUC) that are directly related to pavement condition. For the new road, RUCs do not depend on MS and vary a little bit with increase of traffic volume. However, the difference is remarkable in case of old road where RUCs can be as high as ALL 9,000 per veh-km. The older road case again, as with the 
maintenance costs, is a very good example how RUCs decrease with increase of MS (as well as with increase of funds allocated to routine maintenance).

Table 7: Cumulative 10-year average annual RUCs per veh-km for analyzed paved roads and various traffic volumes, depending on applied MS [ALL] [3]

\begin{tabular}{|c|c|c|c|c|c|c|c|}
\hline $\begin{array}{l}\text { raffic volume } \\
\text { [veh/day] }\end{array}$ & ond & BM & MS5 & MS4 & MS3 & MS2 & MS1 \\
\hline \multirow{2}{*}{$\begin{array}{c}250 \\
\text { (low) }\end{array}$} & & & & & & & \\
\hline & & & & & & & \\
\hline \multirow{2}{*}{$\begin{array}{c}500 \\
\text { (medium) }\end{array}$} & & & & & & & \\
\hline & & & & & & & .74 \\
\hline \multirow{2}{*}{$\begin{array}{l}1,000 \\
\text { (high) }\end{array}$} & & & & & & & .70 \\
\hline & old & & & & & & 4.37 \\
\hline \multirow{2}{*}{$\begin{array}{c}2,500 \\
\text { (very high) }\end{array}$} & & & & & & & $7,056.56$ \\
\hline & older & $9,068.91$ & $8,338.88$ & $8,340.04$ & $8,316.23$ & $8,316.01$ & $7,684.91$ \\
\hline
\end{tabular}

\section{Conclusion}

These estimates of maintenance costs must be seen as estimates only and not precise assessments. The figures calculated herein do not represent precise amounts for maintenance costs required by the municipalities for routine road maintenance, but are an indication of the scale of expenditure which they will need to build up to if they are to implement comprehensive and effective road maintenance strategies designed to keep their roads in reasonable condition. Even with the lowest MS, i.e. BM, it is evident that road maintenance expenditures have to be increased for at least 3 to 4 times comparing to current values in order to preserve asset value.

\section{Acknowledgements}

The research presented in this paper was conducted as a part of the research made during Technical Assistance for the Albanian Development Fund - Regional and Local Roads: Support to Development of Sustainable Road Maintenance Systems. The authors extend their thanks to all authorities for their kind assistance and understanding.

\section{References}

[1] Challenges in the Implementation of Performance Based Contracting for Road Maintenance. Roughton International Ltd, Chandlers Ford, 2016.

[2] Levels of Service and Maintenance Standards Report. Support to Development of Sustainable Road Maintenance Systems in Local Government. Roughton International Ltd., Chandlers Ford, 2016.

[3] Discussion Paper on Maintenance Costs. Support to Development of Sustainable Road Maintenance Systems in Local Government. Roughton International Ltd, Chandlers Ford, 2016. 